\title{
CURSO PRÉ-VESTIBULAR "UNIVERSIDADE PARA TODOS"
}

\author{
"UNIVERSITY FOR ALL" - PREPARATORY COURSE FOR \\ UNIVERSITY ADMISSION EXAM
}

\section{CURSO PREPARATORIO PARA EXAMEN DE INGRESO "UNIVERSIDAD PARA TODOS"}

\author{
Erivan Coqueiro Sousa \\ Cláudio Pinto Nunes ${ }^{2}$
}

\begin{abstract}
Resumo: O presente artigo aborda o curso pré-vestibular Universidade Para Todos (UPT), um projeto do governo do estado da Bahia, perante um movimento de educação popular que prepara estudantes de baixa renda para o acesso ao nível superior. Explana-se, ainda, sobre um curso Pré-Vestibular Social que iniciou, em 2002, no Campus XII, da Universidade Estadual da Bahia (UNEB), em Guanambi, Bahia, que serviu de referência para as discussões do Estado para criar o UPT. Trata-se de uma análise qualitativa baseada em fontes bibliográficas primárias e secundárias (leis e atas), entrevistas abertas realizadas com dois professores fundadores do Curso Pré-Vestibular Social de Guanambi. Os resultados demonstram que o projeto UPT é uma ação de caráter popular que contribui para o acesso ao nível superior, foi criado devido a diversas reivindicações sociais e teve como referência experiências predecessoras que alcançaram êxito.
\end{abstract}

Palavras-chave: Educação Popular - Pré-Vestibular - Universidade Para Todos.

\begin{abstract}
The present article deals with the "Universidade para Todos" (UPT) preparatory course for university entrance exam, a project of the Bahia state government, as a popular education movement, which prepares low-income students for access to higher education. It also explains about a social pre-college entrance examination course that started in 2002 at Universidade Estadual da Bahia (UNEB), Campus XII, in Guanambi, Bahia, Brazil, which was the basis for discussions by the State to create the UPT. This is a qualitative analysis based on primary (laws and minutes) and secondary bibliographic sources and open interviews
\end{abstract}

\footnotetext{
${ }^{1}$ Mestre em Educação pela Universidade Estadual do Sudoeste da Bahia (UESB). Atua como professor de língua inglesa e redação na Prefeitura Municipal de Maetinga (BA). Atua como docente do Programa Nacional de Formação de Professores da Educação Básica (PARFOR) na Faculdade Entre Rios do Piauí (FAERPI). É Coordenador de Projetos Especiais da Prefeitura de Aracatu (BA). É membro do Grupo de Pesquisa Didática, Formação e Trabalho Docente (DIFORT/CNPq). ORCID iD: http://orcid.org/0000-0003-1636-766X. E-mail: erivanconsultoria01@gmail.com

2 Doutor em Educacão pela Universidade Federal do Rio Grande do Norte (UFRN), Pós-Doutor em Educacão pela Universidade Federal de Minas Gerais (UFMG). Atua como professor da Universidade Estadual do Sudoeste da Bahia (UESB), onde é Coordenador do Programa de Pós-Graduação em Educação (PPGED/UESB). É Vice-Presidente Nordeste da Associação Nacional de Pesquisa e Pós-Graduação em Educação (ANPEd). Líder do Grupo de Estudos Didática, Formação e Trabalho Docente (DIFORT/CNPq). ORCID iD: http://orcid.org/0000-0003-1514-6961 . E-mail: claudionunesba@hotmail.com
} 
conducted with two founding teachers of the Curso Pre-Vestibular Social de Guanambi. The results show that the UPT project is a popular action that contributes to access to higher education, it was created because of diverse social claims and it had as reference the previous successful experiences.

Keywords: Popular Education - University Admission Exam - University for All.

\begin{abstract}
Resumen: Este artículo trata sobre el curso preparatorio para el examen de ingreso universitario "Universidad para Todos" (UPT), un proyecto del gobierno del estado de Bahía, Brasil, ante un movimiento de educación popular que prepara a los estudiantes de bajos ingresos para acceder a la educación superior. También explica sobre un curso social preparatorio para el examen de ingreso a la universidad que comenzó en 2002, en el Campus XII de la Universidad Estatal de Bahía (UNEB), en Guanambi, Bahía, Brasil, que sirvió como referencia para las discusiones estatales para crear el UPT. Este es un análisis cualitativo basado en fuentes bibliográficas primarias (leyes y actas) y secundarias, entrevistas abiertas realizadas con dos maestros fundadores del Curso Social Pré-Vestibular de Guanambi. Los resultados muestran que el proyecto UPT es una acción popular que contribuye al acceso a la educación superior, se creó debido a diversos reclamos sociales y se basó en experiencias anteriores que tuvieron éxito.
\end{abstract}

Palavras clave: Educación Popular - Examen de Ingreso Universitario - Universidad para todos.

\title{
Introdução
}

O acesso ao nível superior no Brasil historicamente foi limitado, uma vez que existiam poucas instituições públicas que possibilitassem a formação universitária. Quando foram criadas as primeiras instituições na colônia, em 1808, época que a família real portuguesa veio para o Brasil, iniciou-se a oferta de vagas, que eram poucas e limitadas a um número reduzido de pessoas (SOUSA; NUNES; SOUSA, 2018).

Em 1911 por meio de legislação federal, a exemplo do Decreto no 8.659 de 05 de abril de 1911, estabelece-se exames de admissão ao ensino superior por meio de avaliação escrita, envolvendo, língua vernácula, prova oral referente à história do país e geografia, por exemplo. (SANTOS, 2011). No ano de 1925, outra determinação do governo, limita ainda mais a entrada na educação superior, posto que se estipulou o limite de vagas. Desta forma o acesso ao curso superior torna-se mais difícil e "os que conseguem realizá-lo são as pessoas das classes dominantes, enquanto as das classes periféricas, pelo baio nível de estudo não consegue, ou pouquíssimas conseguem". (SOUSA; NUNES; SOUSA, 2018, p. 368).

Neste contexto de limitação do ingresso ao terceiro nível educacional, diversos grupos sociais, como associações, movimentos estudantis, institutos, criam cursos prévestibulares populares (CPVP). A ideia corrente com frequência neste período é a de necessidade de preparar os candidatos para aquelas que viriam a ser as disciplinas básicas do curso superior a ser seguido. 


\section{Metodologia}

É comum adotar várias estratégias para se fundamentar e desenvolver uma pesquisa consistente. Neste sentido, opta-se pela Investigação Qualitativa (BOGDAN; BIKLEN, 1994). Então, faz-se necessário, inicialmente, a exploração bibliográfica, para descrever o objeto de estudo que, segundo Barros e Lehfeld (2012, p. 34), "é de grande valia e eficácia ao pesquisador porque ela permite obter conhecimentos já catalogados em bibliotecas, editoras, internet". O estudo de material nas fontes citadas corrobora para a escrita no que tange à fundamentação, ao percurso histórico e à legislação.

A técnica da análise documental está presente, haja vista que são analisados decretos, leis, atas que concernem com o referido curso Pré-Vestibular. Utiliza-se a entrevista aberta (BOGDAN; BIKLEN, 1994), a partir de uma conversa intencional para captar "dados descritivos na linguagem do próprio sujeito, permitindo ao investigador desenvolver intuitivamente uma ideia sobre a maneira como os sujeitos interpretam aspectos do mundo". (BOGDAN; BIKLEN, 1994, p. 134). A entrevista aberta é direcionada a dois professores autores do curso Pré-Vestibular Social, da Campus da UNEB, de Guanambi, o qual contribuiu para a elaboração do curso UPT.

\section{Cursos Pré-Vestibulares Populares (CPVP)}

As classes populares, perante o sistema educacional público, composto de problemas na formação escolar básica e com os exames de admissão, reivindicam e lutam por uma preparação que possa corrigir as lacunas do ensino básico, por meio de cursos preparatórios. Há também a luta por maior oferta de vagas e condições de ingresso na universidade. Busca-se contrapor esta realidade educacional excludente. (SOUSA; NUNES, 2017).

Guimarães (1984) destaca a década de 1920 como período em que o número de candidatos ao ensino superior ultrapassou o número de vagas, explicitando um caráter seletivo e excludente, tendo surgido assim aquele que pode ser compreendido como o embrião daquilo que viria ser o que hoje se denominam cursinhos pré-vestibulares.

Segundo Nascimento (1999), nos anos 60, do século passado, principalmente nos anos 70, diversos movimentos sociais, englobando segmentos de mulheres, de ecológicos, culturais, de periferias, étnicos, de educação popular, se mobilizaram em prol de suas demandas. $\mathrm{Na}$ agenda reivindicatória havia a afirmação de suas identidades coletivas, tratamento igualitário sobre direitos educacionais, trabalhistas, respeito às diferenças culturais e liberdade de expressão. Buscava-se "combater as desigualdades e o autoritarismo presentes nos mais diversos aspectos da vida social, tentando estabelecer novas relações entre Estado e sociedade civil, bem como novas relações no interior da própria sociedade civil" (NASCIMENTO, 1999, p. 67).

Concretizou-se, potencialmente, um movimento profícuo de lutas, pontuando na centralidade da pauta a educação e os meios de democratizar o acesso à formação nas instituições de ensino superior público. (CASTRO, 2005). Neste horizonte estrutural consolida-se a reputação tanto do movimento quanto das pessoas que o compõe, 
sendo balizador na expectativa de "superação de deficiências de escolarização por meio da inserção em um espaço coletivo de formação" (ROSISTOLATO; HELAYËL-NETO; XAVIER, 2011, p. 628).

Percebe-se que há uma centralidade de defesa pela melhoria do ensino público, pois a constituição dos pré-vestibulares ratifica um tensionamento da sociedade para que o Estado, entidade responsável obrigatoriamente pela oferta equânime, igualitária da educação básica de maneira que possibilite a todos o acesso ao ensino superior, passasse, efetivamente a cumprir o seu papel.

Esta constatação configura-se como chamariz de reflexão e crítica ao cumprimento da ação estatal no que tange à educação e não exatamente, como é até pensado por alguns, pela reivindicação de uma política pública de cursos pré-vestibulares. Isso reiteraria a distorção e descumprimento da função do Estado. Oliveira, Freitas e Corrêa (2012, p. 2) asseguram que "estes cursos constituem um dos maiores movimentos educacionais da história recente do campo educacional brasileiro, assumindo um protagonismo inegável nas discussões relacionadas ao ensino superior".

Dentre os propósitos primam-se por romper "paradigmas previstos", exclusões históricas e latentes em que os excluídos, como os moradores de favela, filhos de trabalhadores rurais, indígenas, negros, pessoas de classe social desfavorecida economicamente, estudantes de escolas públicas, dificilmente terão êxito escolar e profissional, enveredarão pela marginalidade. Zaluar e Alvito (1999, p. 21) ponderam, por exemplo, que estudar a favela requer "combater certo senso comum que já possui longa história". O processo de identificar o que permite a alguns fugir ao círculo vicioso que leva à exclusão e à marginalidade pode ser tão ou mais útil para propostas de políticas sociais quanto apontar esse círculo vicioso. Macedo (2006) destaca a preocupação desses grupos, caracterizados como subalternos, com o empoderamento cultural, em que eles mesmos dirigem as propostas educacionais, como "os prévestibulares comunitários e as escolas ligadas tanto aos movimentos sociais quanto às reivindicações indígenas" (MACEDO, 2006, p. 339).

O público constitui-se de pessoas oriundas de classes sociais menos favorecidas economicamente que renegados de uma educação pública digna, procuram suprir as lacunas dos conteúdos que não tiveram acesso no ensino médio. Muitos estudantes sentem-se atraídos por estes cursos, já que se apresentam como alternativas possíveis de adentrar no ambiente acadêmico.

A pedagogia presente não apenas atua perante o atendimento dos conteúdos exigidos nos processos seletivos, como também se desenvolve em consonância com a formação política, a conscientização e a reflexão crítica, em diálogo com conhecimentos políticos, históricos e culturais. Caracteriza-se, então, como um em meio de luta pela educação pública e popular.

\section{Curso Pré-Vestibular Universidade Para Todos (UPT)}

O curso UPT é componente de um programa mais amplo, denominado Faz Universitário e este integra-se ao Programa de Educação Tributária da Bahia (PET/BA), 
criado pela Secretaria da Fazenda em parceria com a Secretaria de Educação (SEC), por meio do Decreto $n^{\circ} 8.583$, de 14 de julho de 2003. Este decreto se fundamentou no seu antecedente, isto é, o Decreto 8.080 , de 11 de dezembro de 2001 e foi alterado pelo Decreto $n^{\circ}$ 9.149, de 23 de julho de 2004.

De acordo com Sousa, Nunes e Sousa (2018), o programa almeja, dentre outros objetivos, fornecer condições de igualdade no mercado de trabalho para alunos egressos da Rede Pública, mediante o aprofundamento de estudos com vistas à realização dos processos seletivos de ingresso em Instituições de Ensino Superior (IES), conceder bolsas de estudos ou bolsas-auxílio para cursar o nível superior, proporcionar bolsa de iniciação ao trabalho, conscientizar sobre a função social do imposto e do exercício da cidadania.

Art. $1^{\circ}$ [...] o Faz Universitário visa promover condições de igualdade social no mercado de trabalho para alunos egressos da Rede Pública de Ensino Estadual e/ou Municipal do Estado da Bahia sendo coordenado pela Secretaria da Fazenda e desenvolvido em parceria com a Secretaria da Educação do Estado da Bahia, com os seguintes objetivos:

I - aprofundar os conhecimentos da Educação Básica, adquiridos pelos alunos da Rede Pública de Ensino, visando ao processo seletivo em Instituições de Ensino Superior - IES;

II - subsidiar, mediante Bolsas de Estudo, formação de nível superior para alunos egressos da Rede Pública de Ensino Estadual e/ou Municipal do Estado da Bahia, que vierem a ingressar em IES particulares do Estado;

III - subsidiar, mediante Bolsa-Auxílio, formação de nível superior de alunos egressos da Rede Pública de Ensino Estadual e/ou Municipal do Estado da Bahia aprovados em processo seletivo em IES públicas no Estado da Bahia;

IV propiciar experiência profissional mediante Bolsa Iniciação ao Trabalho, a alunos egressos da Rede Pública de Ensino Estadual e/ou Municipal do Estado da Bahia que cursam em IES públicas no Estado da Bahia;

V - estimular a compreensão da função social do imposto;

VI - incentivar o exercício da cidadania (BAHIA, 2004, p. 2).

Perante estes pressupostos, o Projeto Faz Universitário se divide em duas fases: IPreparando para a Universidade e II- Cursando a Universidade. Na fase I pretende-se capacitar os alunos egressos da rede pública estadual e/ou municipal do estado da Bahia, para elevar a competitividade do aluno para concorrer a processos seletivos, englobando as seguintes condições:

Art. 4\%: I- Universidade para Todos, curso preparatório, com aulas presenciais e/ou à distância, visando ao ingresso de alunos nas IES, incluindo temas relacionados com a formação da cidadania.

II- Tele Aula consiste em aulas apresentadas em blocos, produzidas em estúdio e veiculadas pela televisão.

Art. $5^{\circ}$ - Para a ação Universidade para Todos o público alvo será constituído por estudantes egressos da Rede Pública de Ensino Estadual e/ou Municipal do Estado da Bahia. 
Art. $6^{\circ}$ - Para a Tele Aula, o público alvo será integrado por estudantes baianos (BAHIA, 2004, p. 7).

O Decreto rege ainda, nos artigos sétimo e oitavo, que o curso preparatório Universidade para Todos deve ser ministrado diariamente, isto é de segunda a sextafeira, com duração de 04 horas/aula durante seis meses por ano, com aulas de dez disciplinas: biologia, física, geografia, história, língua estrangeira, literatura, matemática, português, química e redação. Cada disciplina tem a carga horária de 02 horas/aulas semanais. E no caso da Tele Aula, a periodicidade será semanal, com duração de 1 (uma) hora, no período de março a dezembro.

A estrutura organizacional do UPT é coordenada pela Secretaria da Educação (SEC), com execução das ações pelas universidades estaduais, isto é, Universidade do Estado da Bahia (UNEB), Universidade Estadual de Feira de Santana (UEFS), Universidade Estadual do Sudoeste da Bahia (UESB), Universidade Estadual de Santa Cruz (UESC), em vários municípios do estado. (SOUSA; NUNES; 2017). As disciplinas citadas anteriormente devem ser ministradas, de preferência, por professor-monitor a estudantes advindos de escolas públicas. A seleção de alunos e professores ocorre por meio de editais específicos, o que geralmente é realizado pela SEC e as universidades. Há também orientação vocacional destinada aos alunos envolvidos. $O$ Artigo $9^{\circ}$ explica que:
I - As aulas presenciais e à distância abrangerão 10 (dez) disciplinas;
II - Farão parte do conteúdo programático: orientação vocacional, educação fiscal, cidadania e avaliação de conhecimento;
III - As aulas presenciais serão ministradas, preferencialmente, por professor- monitor, selecionado entre os alunos graduandos das IES públicas estaduais, mediante edital;
IV - A seleção dos alunos-cursistas obedecerá aos seguintes requisitos:
a) Ter cursado da $5^{a}$ série do Ensino Fundamental ao $3^{\circ}$ ano do Ensino Médio na Rede Pública de Ensino Estadual e/ou Municipal do Estado da Bahia;
b) Ser selecionado através de processo de avaliação a ser definido em edital específico.
V - Serão publicadas em editais específicos todas as informações referentes à inscrição, seleção e matrícula para aluno-cursista, bem como do professor-monitor que irá ministrar as aulas. (BAHIA, 2004, p. 8).

Outra questão que merece ser pontuada é que ocorrem também atividades complementares, a exemplo de seminários, oficinas, simulados, conforme a agenda (cronograma) estabelecida, de forma autônoma por cada universidade parceira. Os municípios que desejam aderir ao programa Universidade para Todos podem requerer, por meio de ofício, à universidade mais próxima, justificando a necessidade, além de encaminhar cópia do mesmo documento à Coordenação de Desenvolvimento da Educação Superior (CODES).

Segundo o Artigo 41, as despesas decorrentes da fase I (Universidade para Todos e Tele-Aula) "correrão por conta do Projeto 12.362.056.1008 - Implementação de Novas 
Metodologias do Ensino Médio, constante da Unidade Orçamentária 3.11.315 da SEC" (BAHIA, 2004, p. 20).

A fase II do Faz Universitário (cursando a universidade) centra-se no subsídio da formação acadêmica, por meio de bolsas de estudo, bolsas de auxílio ou bolsa de iniciação ao trabalho, do aluno egresso da rede pública da Bahia, aprovado em processo seletivo e matriculado em IES particulares ou públicas do estado. Para tanto é necessário realizar uma inscrição atendendo a critérios específicos, como ter realizado o Exame Nacional do Ensino Médio, não possuir título de curso superior e nem estar cursando outro curso, enquanto usufruir dos benefícios do programa. (BAHIA, 2004). Como esta fase não é o foco deste trabalho, não se adentrará em demais pormenores.

\section{Origem do UPT: Pré-Vestibular Social de Guanambi como inspirador}

Existem várias descrições acerca da origem do Universidade para Todos, abrangendo lutas dos movimentos estudantis populares, pautas reivindicatórias de professores, projetos de extensão de universidades públicas, por exemplo. Farias (2010) sinaliza que o projeto nasceu do "movimento de estudantes e de professores do curso pré-vestibular comunitário Universidade na Comunidade (UNICOM), em 1998, na unidade da UNEB, localizada no município de Serrinha" (FARIAS, 2010, p. 72). Em outros departamentos da UNEB, existiam, também, cursinhos comunitários a exemplo do prévestibular "Alargando o Funil", no município de Teixeira de Freitas, conforme registrado por Farias (2010).

O curso não nasce no interior dos escritórios diplomados, das secretarias de governo, mas sim na pressão popular do movimento estudantil unebiano que elaborou uma proposta de um pré-vestibular gratuito. Iniciou-se, em 1998, com uma turma com professores voluntários e depois a universidade assumiu como sendo um projeto de extensão (FARIAS, 2010). Na ocasião o movimento estudantil realizou uma mobilização envolvendo todos os campi da UNEB, tendo, inclusive, ocupado a reitoria, em Salvador, com uma pauta composta por 15 (quinze) itens de reivindicação, sendo que um deles era exatamente, a exigência da criação de cursos pré-vestibulares gratuitos (FARIAS, 2010).

Esta empreitada estudantil foi bem sucedida, posto que a Secretaria de Educação (SEC) correspondeu positivamente aos anseios por políticas de acesso à educação superior, agindo imediatamente para efetivar a articulação e interlocução entre a Coordenação de Desenvolvimento da Educação Superior (CODES) e as universidades estaduais, no intuito de materializar a implementação do curso Pré-Vestibular Universidade para Todos. Este resultado ratifica a relevância e representatividade do movimento estudantil, sendo percursor da formulação da política, opinando sobre as instâncias institucional, técnica e operacional.

Mediante entrevista realizada com os dois professores autores do Pré-Vestibular Social que iniciou, em 2002, como um projeto de extensão, no Campus XII, da UNEB, em Guanambi, percebe-se a importância dele nas discussões do Estado para criar o UPT. 
Nesta perspectiva, considera-se relevante delinear sobre as circunstâncias que fomentam a criação do Pré-Vestibular Social com suas respectivas ações.

Jon: Víamos as carências das escolas públicas. Tínhamos uma preocupação social com os alunos que não podiam pagar os cursinhos privados que cobravam caro. Os alunos não tinham condição de ingressar na universidade. Começamos o projeto em 2002. O projeto era de extensão.

Ágata: Lá em Montes Claros até hoje tem a experiência dos pré-vestibulares municipais. Então sugerimos que a prefeitura de Guanambi assumisse. Mas a questão burocrática não permitiu. Começamos na UNEB e pedimos para trabalhar de graça. Juntamos eu, das Ciências Sociais e o colega Pedagogo e começamos o curso na forma de intensivo, ou seja, aos sábados o dia inteiro e aos domingos, pela manhã.

Jon enfatiza o caráter social do projeto do curso Pré-Vestibular Social, idealizado na perspectiva de somar esforços para que o projeto pudesse diminuir a defasagem educacional do setor público, por meio de aulas. As dificuldades dos alunos concluintes ou egressos do Ensino Médio repercutiam no ingresso ao nível superior (ROSISTOLATO; HELAYËL-NETO; XAVIER, 2011). Logo, todos os participantes eram isentos de taxas, uma vez que a instituição pública fornece serviços gratuitos à população.

Ágata pondera que devido ao conhecimento de pré-vestibulares mantidos pelo poder público municipal, em Montes Claros, no Estado de Minas Gerais, sugeriu que a prefeitura de Guanambi alocasse recursos para a execução do projeto. Neste sentido, infere-se que seria possível que ocorresse diariamente, de segunda a sexta-feira e não somente "aos sábados o dia inteiro e aos domingos, pela manhã" (ÁGATA), conforme iniciou na UNEB, posto que não havia recursos para o projeto. Os idealizadores trabalhavam voluntariamente para que o projeto fosse colocado em prática, de forma intensiva, somente sábado e domingo, atendendo a comunidade local.

O projeto do cursinho foi expandido para os campi IX e XVII da UNEB, em Barreiras e Bom Jesus da Lapa, respectivamente. Isso ocorreu porque uma docente idealizadora do projeto também trabalhava em Bom Jesus da Lapa e um terceiro professor do campus de Guanambi, que não foi o autor do projeto, mas que se interessou por ele, implementou em Barreiras.

O projeto, em Guanambi, foi recebendo adesões voluntárias de outros professores e estudantes do campus, constituindo um "efeito dominó", por conta da sensibilização enquanto a importância dele.

Jon: Começou na universidade com o apoio dos professores e dos discentes dos cursos de Pedagogia e Educação Física, os quais desenvolviam atividades de extensão com os alunos do Pré-Vestibular. Fazíamos visitas às famílias.

Ágata: Os estudantes ajudavam nas funções voluntariamente. Houve reservas de professor. Cada um ministrava aulas conforme sua disponibilidade. Alguns alunos de pedagogia começaram a dar aulas gratuitas.

A fala de ambos os entrevistados condiz com a cooperação voluntária de outros atores sociais, professores e estudantes, os quais se propõem a colaborar quer seja ministrando aulas, quer seja atuando em atividades de extensão, envolvendo o público 
do Pré-Vestibular Social. "O corpo docente e coordenadores [...] costumeiramente, tem forte engajamento político-social [...]. Atuam, na maioria, de forma voluntária. A maior parte está se graduando, ainda em processo de formação" (SOUSA; NUNES; SOUSA, 2018, p. 7), seja em licenciatura ou bacharel.

A comunidade atendida, neste viés, sente-se inserida no universo pré-universitário, a universidade é de pertença social, pública, logo todos podem conseguir a aprovação no vestibular, com vistas a, de fato, pertencer à graduação.

\begin{abstract}
Sobre o Projeto Pré-Vestibular Social [...] foi feita a apresentação do cronograma pelo professor [...] que também solicitou apoio de outros professores do departamento e de alunos que já estejam cursando o $5^{\circ}$ semestre. Tal projeto é destinado a alunos de baixa renda, oriundos da escola pública (ATA CAMPUS XII UNEB, 2002, n. 16, p. 27b).
\end{abstract}

A ata número dezesseis da reunião de departamento da UNEB, do dia dezenove, do mês de setembro, do ano de dois mil e dois comprova que o Projeto do PréVestibular Social já compõe a agenda da instituição com relevância, é uma ação oficial, registrada. O professor citado reforça a solicitação de apoio de colegas e discentes, o que é registrado, por ser considerado relevante. O redator da ata enfatizou o fundamento e objetivo social, comunitário do cursinho, sendo basilar para a adesão de mais colaboradores. O texto da ata corrobora com as informações proferidas pelos professores entrevistados.

Os depoentes mencionam que havia palestrantes, psicólogos para orientar, oficinas, seminários de redação, palestras interacionistas. O número de aprovados nos processos seletivos vestibulares, no ENEM, aumentava a cada ano, sendo superior ao número de aprovados nos cursinhos privados. (JON). Os resultados positivos do projeto são repercutidos, o que influencia na proposta de criação do curso UPT.

Ágata: O projeto foi crescendo. Entramos na mídia. O reitor da UNEB (da época) mandou nos chamar. $O$ reitor viu com o governo do estado para levar para outros lugares. Ele perguntou se nós aceitávamos o governo, por meio da secretaria de educação (SEC), assumir o projeto, como projeto de governo.

Jon: O Pré-Vestibular Social foi aprovado no Plano Operativo Anual (POA). A UNEB e a SEC apoiaram o projeto que passou a ser executado em todos os campi da instituição.

A fala dos dois entrevistados ratifica que, após alguns anos de execução do cursinho Social em Guanambi e em Bom Jesus da Lapa e Barreiras, o reconhecimento do trabalho ultrapassa as fronteiras dos campi citados, sendo difundido pela imprensa, tendo impacto positivo em toda a comunidade acadêmica unebiana e no âmbito político estadual. A disseminação das experiências dos cursinhos foi decisiva no reconhecimento. (CASTRO, 2005). Diante disso, o reitor da UNEB dialoga com o governo estadual para inserir o projeto no calendário de ações, alocando recursos para que ele seja executado em toda a Bahia e se torne uma política pública (ÁGATA).

Neste interim, o reitor convidou os autores do projeto para reuniões com o governo do estado e a secretaria de educação para as devidas discussões, resultando na aprovação, por parte de todos os envolvidos, no que tange a abranger o projeto para 
todo o estado. Conseguiu-se a aprovação do projeto no Plano Operativo Anual, garantido recursos financeiros por parte do estado e da UNEB (JON).

Na ocasião o projeto do Pré-Vestibular Social, representado pela UNEB, foi explicado perante todas as etapas "desde o fato gerador, passando pela investigação científica, as possibilidades de solução, encaminhamentos, concluindo com os resultados obtidos" (UNEB, 2006, p. 9). A SEC aprovou a proposta e, no mesmo ano, por meio da CODES, convidou as quatro universidades estaduais baianas (UNEB, UEFS, UESC e UESB) para participarem da elaboração do projeto definitivo que passou a ser chamado de Universidade para Todos.

Em agosto de 2003 o UPT foi lançado, em Salvador, em uma cerimônia que contou com a presença do governo, da equipe de coordenação, professores especialistas, professores monitores e técnicos das universidades.

\begin{abstract}
A cerimônia histórica de abertura teve início às 08 horas e 30 minutos no Ginásio de Esportes do Colégio Odorico Tavares, em Salvador e, simultaneamente, na mesma data e horário o Projeto teve início nos municípios do interior do estado, contando com a presença de prefeitos, secretários das DIREC's locais (UNEB, 2006, p. 10).
\end{abstract}

Salienta-se que nesta dicotomia de um grande contingente de concluintes e egressos do ensino médio, visionários de progressão nos estudos de cunho superior, perante o alto índice de concorrências dos processos seletivos vestibular, emerge esta bandeira social com vistas a suprir lacunas que a escola pública não conseguiu contemplar. Mesmo com as iniciativas predecessoras engendradas pelos movimentos sociais, neste caso, o movimento estudantil, a universidade também se sensibilizou com esta causa e aderiu à proposta do curso pré-vestibular. Isso comprova o empenho de que a demanda social existente seja correspondida, por meio de políticas públicas.

\title{
Considerações finais até o momento
}

O curso UPT emanou de lutas populares em prol de diminuir as defasagens da educação básica, preparando estudantes para ingressarem ao nível superior de ensino. Em consonância está a agenda por melhorias na estrutura educacional e expansão universitária pública. Este projeto, assim como outros CPVP, constitui importante espaço de mobilização social que possibilitou conquistas relacionadas às cotas raciais e sócias nas instituições de ensino superior públicas.

Este projeto atende a uma parcela da população com menores condições financeiras e "contribui muito para alavancar a autoestima, os níveis de conhecimento dos estudantes, com vistas a ingressar ao ensino superior" (SOUSA; NUNES, 2017, p. 1128). Neste interim, destaca-se a importância do empenho dos profissionais, no tocante a trabalhar a autoestima discente e os conteúdos exigidos nos exames da admissão mediante às exigências dos processos seletivos.

Não se deve atribuir a conotação de meros paliativos sociais aos CPVP, mas considerá-los como importante mecanismo e/ou política pública que fomenta a postura do estudante com vistas a superar dificuldades e atingir o objetivo de ingresso na educação terciária. É sabido ainda que, conforme a Lei de Diretrizes e Bases da Educação 
(LDB) no 9394/1996, no Artigo 43, incisos do I ao VI, a educação superior estimula a criação cultural e sua respectiva difusão, o desenvolvimento científico e tecnológico e o pensamento reflexivo. Procura-se, estimular o conhecimento dos problemas do mundo presentes, de maneira que, capacitadas, as pessoas, conheçam os problemas nacionais e regionais, visando atuar na comunidade de forma contundente, contribuindo para a melhoria da qualidade de vida em diversos aspectos.

\section{Referências}

ATA CAMPUS XII, UNEB. Ata No 16, da Reunião do Departamento de Educação, do Campus XII da Universidade do Estado da Bahia, em Guanambi-BA, realizada em 19 de setembro de 2002.

BAHIA. Decreto $\mathbf{n}^{\circ} \mathbf{8 . 0 8 0}$, de 11 de dezembro de 2001. Regulamenta os incisos I e II do artigo $2^{\circ}$ da Lei $n^{\circ} 7.979 / 01$ que passa a ser denominado Programa Estadual de Incentivo à Formação Universitária: Faz Universitário e dá outras providências. Disponível em: https://governo-ba.jusbrasil.com.br/legislacao/78285/decreto-8080-01. Acesso em: 30 jan. 2018.

BAHIA. Decreto $\mathbf{n}^{\circ} \mathbf{8 . 5 8 3}$, de 14 de julho de 2003. Aprova o Regulamento do Programa Faz Universitário vinculado ao Programa de Educação Tributária do Estado da Bahia e dá outras providências. Disponível em: https://governo-ba.jusbrasil.com.br/legislacao/77500/decreto8583-03? print=true. Acesso em: 30 jan. 2018.

BAHIA. Decreto $\mathbf{n}^{\circ}$ 9.149, de 23 de julho de 2004. Aprova o novo Regulamento do Programa Faz Universitário vinculado ao Programa de Educação Tributária do Estado da Bahia, e dá outras providências.

Disponível

em:

http://www.sec.ba.gov.br/uptsys/arquivos/decreto 9149 de 23 de julho de 2004 faz universita rio e upt.pdf. Acesso em: 30 jan. 2016.

BARROS, Aidil de Jesus Paes de; LEHFELD, Neide Aparecida de Souza. Projeto de pesquisa: propostas metodológicas. 21. Ed. Petrópolis, RJ: Vozes, 2012

BOGDAN, Robert C; BIKLEN, Sari Knopp. Investigação Qualitativa em educação. Porto Editora, LDA, 1994. Porto: Portugal.

BRASIL. Decreto nº. 8. 659, de 05 de abril de 1911. Aprova a Lei Orgânica do Ensino Superior e do Fundamental na República. Disponível em: http://www2.camara.leg.br/legin/fed/decret/19101919/decreto-8659-5-abril-1911-517247-publicacaooriginal-1-pe.html. Acesso em: 02 nov. 2019.

CASTRO, Cloves Alexandre de. Cursinhos alternativos populares: Movimentos territoriais de luta pelo acesso ao ensino superior público no Brasil. Dissertação. (Mestrado em Geografia) Faculdade de Geografia, Universidade Estadual Paulista, São Paulo, 2005.

FARIAS, Maria Auxiliadora Ornellas. Projeto Universidade para Todos: política pública na direção da igualdade de oportunidades ao acesso à educação superior. 2010. 189 f. Dissertação (Metrado em Políticas Públicas), Universidade do Estado da Bahia, Salvador. Disponível em: http://www.cdi.uneb.br/site/wp-content/uploads/2016/01/maria_auxiliadora_ornellas_farias.pdf. Acesso: em 20 jan. 2017.

GUIMARÃES, Sônia. Como se faz a indústria do vestibular. Petrópolis: Vozes, 1984.

MACEDO, Elizabeth. Por uma política da diferença. Cadernos de pesquisa, v. 36, n. 128, p. 327356, maio/ago. 2006. Disponível em: http://www.todosnos.unicamp.br:8080/lab/acervo/artigosde-periodicos/MACEDO\%20Por\%20Uma\%20Politica\%20Da\%20Diferenca\%20p327-

356.doc/view. Acesso em: 20 ago. 2018. 
NASCIMENTO, Alexandre do. Movimentos Sociais, Educação e Cidadania: Um estudo sobre os Cursos Pré-Vestibulares Populares. Orientadora: Prof a Dra Maria Julieta Costa Calazans. Rio de Janeiro: Universidade do Estado do Rio de Janeiro (UERJ), 1999. Dissertação de Mestrado em Educação.

OLIVEIRA, Cícero Santiago de; FREITAS, Alith Moura de; CORRÊA, Marcos Britto. Contribuições dos cursos pré- vestibulares populares no fortalecimento da educação popular no Rio Grande do Sul, $2012 . \quad$ Disponível em: http://coral.ufsm.br/sifedocregional/images/Anais/Eixo\%2008/C\%C3\%ADcero\%20Santiago\%20d e\%200liveira.pdf. Acesso: em 02 out. 2019.

ROSISTOLATO, Rodrigo Pereira da Rocha; HELAYËL-NETO, Jose Abdalla e XAVIER, Marcel Duarte da Silva. Juventudes populares em um pré-vestibular: a construção coletiva de expectativas e campos de possibilidades educacionais. Revista brasileira de Estudos Pedagógicos, Brasília, v. 92 n. 232, p. 616-638, set./dez. 2011. Disponível em: http://rbep.inep.gov.br/index.php/rbep/article/view/670/648. Acesso em: 12 nov. 2017.

SANTOS, Janete dos. Política pública de acesso ao ensino superior: um olhar sobre a utilização do ENEM/SISU na Universidade Federal do Recôncavo da Bahia. Salvador: XI CONLAB, 2011. Disponível

em http://www.xiconlab.eventos.dype.com.br/resources/anais/3/1308337559 ARQUIVO Artigoconla b1.pdf. Acesso em: 05 jun. 2018.

SOUSA, Erivan Coqueiro; NUNES, Claudio Pinto. Acesso de estudantes dos meios populares ao Ensino Superior: um estudo do curso pré-vestibular universidade para todos no município de Aracatu-BA.2017. Disponível

em: http://periodicos.uesb.br/index.php/semgepraxis/article/viewFile/7276/7059. Acesso em: 02 out. 2019.

SOUSA, Erivan Coqueiro; NUNES, Claudio Pinto; SOUSA, Gilvan. Curso Pré-Vestibular Universidade Para Todos: Contribuições para o acesso de estudantes ao Ensino superio e ao Mercado de Trabalho. Relações Sociais, Viçosa, v. 01, n. 03, p. 367-381, out/2018. Disponível em: https://periodicos.ufv.br/ojs/reves/article/view/3188/1517. Acesso em: 02 out. 2019.

UNEB. Avaliação do projeto universidade para todos. Salvador: EDUNEB, 2006.

WHITAKER, Dulce Consuelo Andreatta. Da “invenção” do vestibular aos cursinhos populares: Um desafio para a Orientação Profissional. Revista Brasileira de Orientação Profissional. jul.-dez. 2010, Vol. 11, No. 2, 289-297. Disponível em: http://pepsic.bvsalud.org/scielo.php?script=sci arttext\&pid=S1679-33902010000200013. Acesso em: 10 out. 2017.

ZALUAR, Alba; ALVITO, Marcos. Introdução. In: . (Org.). Um século de favela. Rio de Janeiro: Ed. FGV, 1999. p. 7-24.

Submetido em: $\quad$ 18-11-2019
Aceito em:

